\title{
Preservação da saúde infantil no ensino do piano*
}

\author{
Preservation of the children's \\ health at the piano teaching
}

por Maria Bernardete Castelan Póvoas

e Mariana Costa Chamas Tabacow

\section{RESUMO}

Neste artigo são abordados fundamentos teóricos de estudos anátomo-fisiológicos do corpo humano, os quais podem auxiliar no ensino de piano para crianças. Através do conhecimento destes, o professor compreende basicamente os processos corporais pelos quais a criança passa e torna-se sensível à observação e análise de características apresentadas por cada aluno, o que intervém significativamente na maneira com a qual o ensino é procedido. Essa pesquisa resultou de um levantamento bibliográfico onde foram exploradas algumas das áreas que estudam os aspectos anátomo-fisiológicos do homem. As principais fontes de pesquisa aqui utilizadas foram as publicações de Marcondes (1980) e Rasch (1991). A primeira parte do trabalho é constituída de uma introdução sobre o processo de formação e desenvolvimento ósseo na infância, seguida de uma breve inserção na área de cinesiologia (segunda parte). A conexão desses estudos sobre o corpo humano com o ensino do piano encontra-se na terceira e última parte, na qual são apontados e discutidos alguns fatores que devem ser pré-avaliados pelo professor do instrumento, sempre de acordo com as características de cada aluno. Concluiu-se que a consciência destes aspectos é de grande importância para o ensino bem-sucedido do piano.

Palavras-chave ensino do piano para crianças; formação óssea; cinesiologia

\section{ABSTRACT}

In this article are approached theoretical foundations of anatomy and physiology of the human body, which can be useful when teaching the piano for children. Through this knowledge, the teacher comprehends basically the body processes that the child goes through and becomes sensitive to the observation and analysis of the characteristics presented by each student, what interferes significantly on the way the education is proceeded. This research resulted from a bibliographic survey in which were explored areas that study anatomic and physiological aspects of the human being. The main sources used were publications by Marcondes (1980) and Rasch (1991). The first chapter of the article is an introduction about the formation and development of 


\section{Preservação da saúde infantil no ensino do piano*}

Preservation of the children's health at the piano teaching

por Maria Bernardete Castelan Póvoas e Mariana Costa Chamas Tabacow

the bones during the childhood, followed by a short insertion in the kinesiology area (second chapter). The connection of the studies about the human body with the piano teaching is made in the third and last chapter, in which some factors that should be prejudged by the teacher of the instrument, according to the characteristics of each student, are pointed out and discussed. The conclusion is that the conscience of these studies is a matter of great importance for the successful teaching of the piano.

Keywords piano teaching for children; bones formation; kinesiology 


\section{Introdução}

Com este artigo busca-se trazer uma contribuição para o ensino de piano para crianças, através da reflexão sobre conhecimentos pertinentes às estruturas do corpo humano e a conscientização deste. A ausência da conscientização corporal, ou seja, a falta de atenção às formas e estados naturais do corpo, pode tornar problemático o desempenho de uma atividade motora otimamente, causando, em consequência disso, lesões e traumatismos. 0 foco foi dado ao corpo no processo de desenvolvimento do aprendizado no instrumento musical que é, certamente, um fator importante no aprendizado/prática de qualquer atividade presente na vida do ser humano. Por esse motivo, o professor de atividades em que o controle motor é essencial para sua efetivação deve estar consciente sobre aspectos básicos não somente os referentes ao processo de formação óssea (anatomia), mas também aqueles relacionados à cinesiologia, biomecânica, ergonomia, entre outros estudos focados no corpo humano.

Foram elaboradas observações fundamentais a respeito da formação óssea e do movimento do corpo, tendo em vista as áreas da anatomia e da cinesiologia. Algumas informações dessas áreas referentes ao movimento corporal têm forte influência qualitativa sobre a didática do piano. 0 conhecimento aqui explorado pode beneficiar a prática do ensino através da conscientização e consequente preservação do desempenho músico-corporal. Grande parte das informações aqui contidas teve embasamento em publicações destacadas no levantamento bibliográfico proposto, principalmente no artigo "Idade Óssea em Pediatria" por Eduardo Marcondes, publicado em 1980 na Revista Pediatria, que compõe a primeira parte do artigo, e na $7^{a}$ edição do livro "Cinesiologia e Anatomia Aplicada", publicado em 1991 e escrita por Philip J. Rasch, que compõe a segunda parte do artigo. Após a investigação dos dois assuntos foi ressaltada a convergência dos mesmos com o ensino do piano para crianças, onde se estabeleceu a terceira e última parte do trabalho. Nela foram expostos aspectos de importante consideração durante o processo de ensino, alguns deles propostos pela autora e outros originados de consulta bibliográfica, como nos métodos para piano escritos por Guilherme Fontainha e Cláudio Richerme.

\section{O Processo de Formação Óssea na Infância}

Do nascimento até a maturidade, o ser humano passa por uma série de processos de formação e transformação em seu corpo. Algumas estruturas têm seu desenvolvimento iniciado no estágio fetal e finalizado ainda na infância; outras têm seu processo concluído apenas por volta dos 20 anos, aproximadamente quando 0 indivíduo atinge a idade adulta. Sobre o foco desta parte do estudo, as estruturas ósseas, Marcondes (1980, p. 298) diz que: “0 corpo humano apresenta 800 centros 
de ossificação, em que metade deles já se desenvolve na vida intra-uterina". ou seja, a outra metade dos centros de ossificação no corpo humano desenvolve-se apenas após o nascimento e, portanto, até a idade adulta.

0 desenvolvimento do esqueleto é realizado através de dois processos: 0 do crescimento e o da maturação óssea. Estes dois processos iniciam e finalizam juntos, atingindo assim, a maturidade. Ainda de acordo com Marcondes:

Maturidade é um produto final, um estado acabado e maturação pode ser entendida como o processo através do qual o ponto final é atingido. A maturidade morfológica é inevitável para todos os indivíduos, porém chega mais cedo na vida para uns e mais tarde para outros (...). (MARCONDES, 1980, p. 297).

É através dessa afirmação que se pretende, neste artigo, despertar uma consciência da enorme responsabilidade a qual professores de piano estão sujeitos ao lidar com crianças cujas estruturas, tão sensíveis, encontram-se ainda em formação. Ao lecionar, os professores estão participando diretamente dos processos de crescimento e maturação óssea do indivíduo jovem, sendo uma de suas responsabilidades que a maturidade (estado acabado) de um aluno em fase de crescimento seja atingida sem alterações no andamento e forma naturais ao processo.

Não há uma previsão exata para o momento em que a criança atingirá a maturidade. Uma aproximação é concebida através da denominada 'idade óssea', que é o índice de desenvolvimento do esqueleto. Como citado anteriormente, é um acontecimento que pode vir "mais cedo para uns e mais tarde para outros" (MARCONDES, 1980, p. 297). No entanto, é comum a todos os indivíduos que vários aspectos, tais como: hereditários, nutricionais, socioeconômicos, estão ligados a este processo.

0 processo de mineralização', pelo qual os centros de ossificação passam, concentra-se nos tecidos cartilaginosos preexistentes dos núcleos nos ossos curtos e nas epífises $^{2}$ dos ossos longos. Paralelamente, o crescimento dos ossos longos ocorre através da cartilagem de conjugação ${ }^{3}$. A ocorrência da completa ossificação desta coincide com o momento em que o osso atinge sua dimensão e forma final, ou seja, cessa seu crescimento. É um processo bastante longo, levando em conta que sua formação é apenas concluída no momento em que a idade adulta é atingida.

Mais precisamente, no caso do ensino do piano, serão destacadas informações

\footnotetext{
1 Substituição de matéria orgânica por constituintes minerais.

2 A epífise (do latim epi, sobre + physis, crescimento) é a parte de um osso longo que se desenvolve por um centro de ossificação diferente do corpo do osso, ou diáfise, e que dele é separado por uma camada de cartilagem.

3 Faixa transversal de tecido cartilagíneo que reúne a diáfise e a epífise de um osso longo, ao nível da qual se efetua o crescimento em comprimento desse osso. Sin. de cartilagem diáfiso-epifisária.
} 
sobre a formação óssea das estruturas da mão: carp $0^{4}$, metacarpo $0^{5}$ e falanges (distais, médias e proximais). De acordo com as descrições anatômicas, distal se refere ao que se encontra em uma configuração espacial periférica, ou seja, mais afastado do centro, contrário de proximal, conforme a figura que segue ilustra.

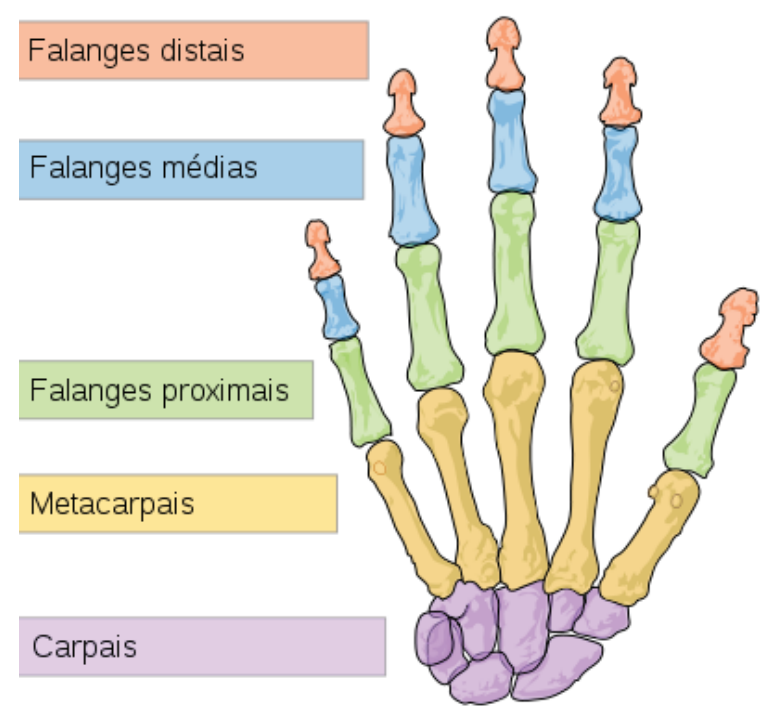

Figura 1. Estruturas ósseas da mão e punho Fonte: Wikipédia

0 surgimento do primeiro núcleo de ossificação da mão se dá aproximadamente entre os três e seis meses de idade, com 0 'grande osso' $^{\prime}$ e o 'ganchoso'. Os últimos a surgir no carpo são: o psiforme', com 10 anos, e o sesamóide` do adutor do polegar, com 12 anos e oito meses no sexo masculino e 10 anos e um mês no sexo feminino (Figura 2). Nota-se uma diferença de dois anos e sete meses de um sexo para outro, não somente se tratando do sesamóide, mas dos demais núcleos de ossificação também. É comprovado que a maturidade é atingida mais cedo em meninas do que em meninos. Na figura seguinte são mostrados, de maneira mais detalhada, os núcleos de ossificação da mão e pulso, onde estão denominados e organizados em ordem de surgimento.

4 Parte do esqueleto da mão que se articula com o antebraço.

5 Parte compreendida entre o punho e os dedos.

6 Localizado na região central do carpo.

7 Localizado à esquerda do 'grande osso'.

8 Quarto osso da primeira fila do carpo.

9 Diz-se dos ossos arredondados e pequenos que se localizam junto das articulações. 


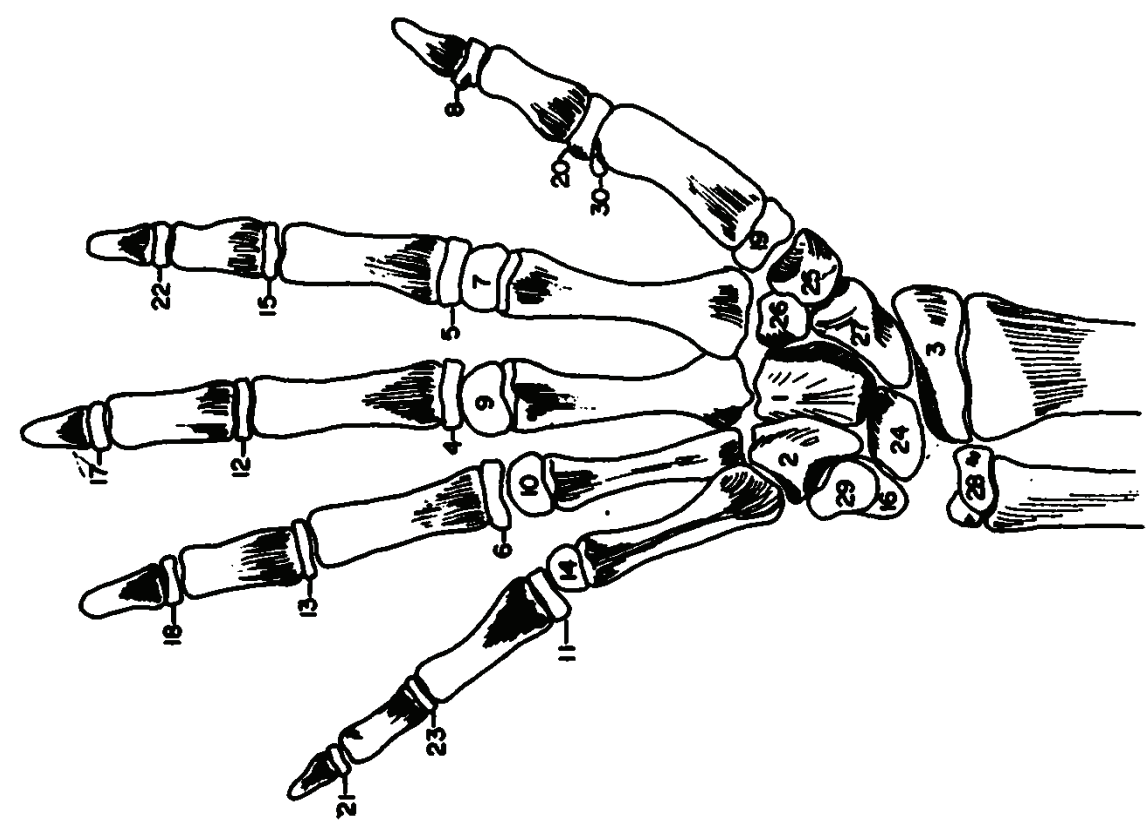

1. Grande 0 sso

2. Ganchoso

3. Distal da epífise do rádio

4. Epífise da falange proximal do $3 .^{\circ}$ dedo

5. idem do $20^{\circ}$ dedo

-6. idem do $4 .^{\circ}$ dedo

7. Epifise do metacarpo II

8. Epifise da falange distal do $10^{\circ}$ dedo

9. Epifise do metacarpo III

10. Epifise do metacarpo IV

11. Epífise da falange proximal do $5 .^{\circ}$ dedo

12. Epífise da falange média do $3 .^{\circ}$ dedo

13. idem do $4 .^{\circ}$ dedo

14. Epífise do metacarpo V

15. Epífise da falange média do $2 .^{\circ}$ dedo

16. Piramidal

17. Epifise da falange distal do $3 .^{\circ}$ dedo

18. idem do $4 .^{\circ}$ dedo

19. Epífise do metacarpo I

20. Epifise da falange proximal do $10^{\circ}$ dedo

21. Epifise da falange distal do $5 .^{\circ}$ dedo

22. idem do $2 .^{\circ}$ dedo

23. Epífise da falange média do $5 .^{\circ}$ dedo

-24. Semilunar

-25. Trapézio

-26. Trapezóide

-27. Escafólde

28. Epifise do cúbito

29. Pisiforme

30. Sesamóide do adutor do polegar

Figura 2. Ordem de aparecimento dos núcleos de ossificação da mão e do punho. Fonte: MARCONDES, 1980, p. 300 
0 mosaico formado por todas essas "peças", de tamanhos, idades, sensibilidades e funções distintas, é de grande minudência. Sua forma natural, assim como muitas estruturas encontradas na natureza, é de extrema complexidade e eficiência. A figura seguinte mostra uma "representação geométrica da mão (por Littler) [...] com os dedos estendido e abduzido, as pontas digitais ficam localizadas na circunferência de um círculo cujo centro fica na cabeça do terceiro metacarpo." (LITTLER, apud TUBIANA; THOMINE; MACKIN, 1996, p. 8).

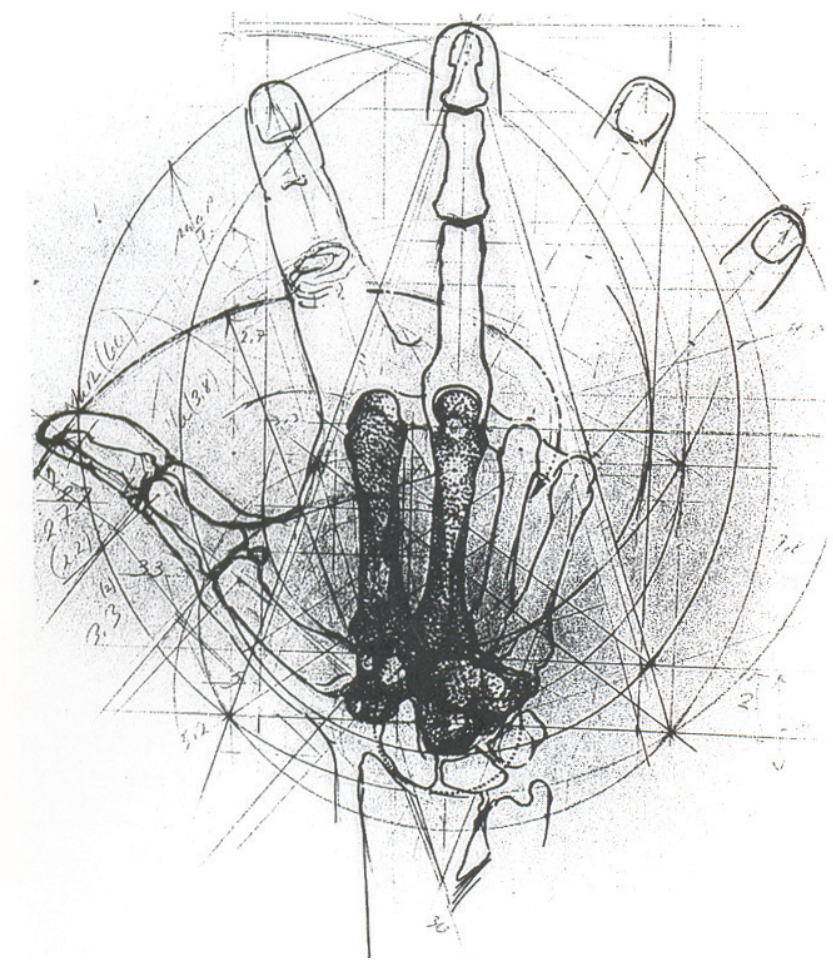

Figura 3. Representação geométrica da mão por Littler. Fonte: LITTLER, s/d, apud TUBIANA; THOMINE; MACKIN, 1996, p. 8)

\section{A Ciência do Movimento - Cinesiologia}

A palavra 'cinesiologia' provém dos verbos gregos "kinein"; que significa mover; e "logos"; estudar. É a ciência que estuda o movimento do corpo.

0 movimento é constituído por movimentos de postura, transporte, manipulação e tremor (involuntário), cada um controlado por seu próprio feedback sensitivo. 0 cérebro coordena e regula estes feedbacks. 0 aprendizado, portanto, baseia-se na integração, pelo cérebro, das relações anatômicas $e$ fisiológicas entre os sistemas eferentes ${ }^{10}$ e aferentes. (RASCH, 1991, p. 9).

10 Que vão dos centros nervosos para a periferia (opõe-se a aferente.). 
Para melhor compreender como ocorre o aprendizado e a reprodução de movimentos através do corpo é necessário explorar áreas que estudam o cérebro e seu funcionamento, como por exemplo, a psicologia cognitiva, a qual estuda a aquisição dos conhecimentos. Contudo, a cinesiologia estrutural, por ser uma área bastante ampla, possui uma subárea relacionada à psicologia que é chamada de "cinesiologia simbólica". Esta é, segundo Rasch (1991, p.10), “o estudo das reciprocidades do movimento e significado, no que concerne a tópicos como imagem corpórea, auto-imagem, expressão estética, comunicação cultural, personalidade, motivação e auto-percepção." Ao atentar para essa área, o professor trabalha aspectos como a satisfação, segurança e confortabilidade da criança ao praticar, fazer aulas e se apresentar em público. Segundo Frank e Mühlen (2007, p. 190): “Frequentemente, muitos problemas de saúde, inclusive a ansiedade de palco, têm a sua origem nesse estágio do aprendizado musical." Tal declaração indica que além dos estudos aqui feitos sobre o corpo humano, há ainda outro horizonte a ser explorado que pode auxiliar no processo de ensino/aprendizagem, que é o da mente, a cognição"

As outras subáreas da cinesiologia estrutural, que tratam do movimento físico, são: cinesiologia funcional, fisiologia do exercício, biomecânica, cinesiologia do desenvolvimento e comportamento motor.

Além da relação que o homem possui com o seu próprio desenvolvimento e suas ações, ele está também em permanente correlação com o ambiente em que habita. Qualquer atitude que o homem tenha em relação ao seu habitat, interagindo com ele ou modificando-o, exercerá uma influência direta sobre seu próprio organismo. Sendo assim, ele detém um poder significativo sobre muitas das mudanças que ocorrem ao seu redor e, consequentemente, em si mesmo. Rasch (1991, p. 9) afirma que:

As modificações que um homem faz em seu ambiente causam uma alteração da entrada desse ambiente para seu organismo. o feedback destas alterações funcionais afeta sua estrutura. As mudanças da estrutura influenciam a relação entre os diversos componentes e acarretam alterações na função. Assim, até certo ponto, o homem é o seu próprio arquiteto.

Desta forma, o organismo do homem pode ser vítima de suas próprias ações, como também pode sofrer influência de fatores externos, o que inclui a ação de terceiros e neste caso, pode ser tomada a relação professor/aluno como exemplo.

Fazendo uma analogia da afirmação feita por Rasch (1991) com o ensino do piano para crianças, poder-se-ia dizer que modificações que ocorrem durante o processo de aprendizado são em grande parte fruto dos conhecimentos transmitidos pelo professor à criança. Em consequência, há alterações no corpo da criança que re-

11 Ato ou processo de conhecer, que envolve atenção, percepção, memória, raciocínio, juízo, imaginação, pensamento e linguagem. 
fletem no aprendizado de determinada tarefa. Essa aplicação prática que o corpo procede, de acordo com a informação absorvida, pode alterar a funcionalidade dos membros ou segmentos do corpo envolvidos na prática instrumental. Tais alterações podem tornar-se um aspecto positivo, como por exemplo, no aprimoramento da força muscular, ou no aprendizado/melhoria do desempenho de uma habilidade motora; mas também pode advir um aspecto negativo, como o atrofiamento muscular em um segmento, a deformação de uma estrutura óssea em processo de mineralização, entre outros. Concluindo, ao ensinar uma atividade ou ação motora a uma criança o professor está sendo, de certa maneira, seu arquiteto. Está sob seu poder preservar a saúde da criança, respeitando as formas e estados naturais de seu corpo, ou causar alterações funcionais que afetem sua estrutura, comprometendo suas capacidades inatas.

\section{Aplicando conhecimentos corporais à didática do piano}

0 piano é um instrumento que envolve um trabalho global do corpo do instrumentista em sua performance. Além de todos os membros superiores (cintura escapular, braço, antebraço, pulso, mão e tronco), participam também da performance os membros inferiores, que funcionam como ponto de equilíbrio do corpo e são peça-chave no funcionamento da mecânica acionada pelos pedais. Por isso é válido afirmar que a relação estabelecida entre o corpo e o instrumento deve ser harmoniosa. Uma das formas de fazê-lo é pesquisando a respeito das ciências aqui abordadas, para que sua compreensão traga benefícios à prática. "Há necessidade de um método, de um processo de ensino, baseado em dados fisiológicos e psicológicos compreensíveis ao aluno, que só aceita aquilo que compreende." (FONTAINHA, 1956, p. 9). Como veremos ao longo dessa parte, há livros que discorrem a respeito da técnica pianística e apoiam o conhecimento, tanto do professor como do aluno, dos estudos sobre as ciências do corpo humano.

Alguns teóricos da técnica pianística, como Steinhausen e Kaemper, criticam seus colegas que fazem grandes descrições anatômicas do braço, classificando tais descrições de um eruditismo inútil e complicado demais para que possam ter alguma utilidade prática. Mas verdade é que alguns conhecimentos anatômicos e fisiológicos específicos podem de fato trazer conclusões importantes em nível prático, embora muitos autores não tenham sabido tirar lucros que compensassem tais conhecimentos. Para avaliar a importância de um estudo nesse sentido, bastaria o exemplo clássico do pianista e compositor Robert Schumann que, insatisfeiro com o seu desempenho técnico, construiu aparelho inadequado para exercitar seu dedo anular, que acabou paralisado. Isso por ignorar alguns princípios da fisiologia articular dos dedos, bem como opções mais adequadas para tentar resolver seus problemas técnicos. (RICHERME, 1996, p. 36). 
Ao dar aulas a uma criança, há uma série de fatores que devem ser atentados, a fim de evitar os que põem sua saúde em risco. Um fator potencialmente danoso, por causar deformações, é a intensidade excessiva de força realizada pela criança. A proficiência no desempenho de uma habilidade, segundo Guthrie (1952, p. 136), "consiste na capacidade de atingir algum resultado final com o máximo de certeza e um mínimo dispêndio de energia ou de tempo e energia". Os princípios dessa afirmação vão contra a prática de qualquer atividade motora na presença de tensão excessiva, que causa maior dispêndio de energia, levando-se em conta que o músculo estará sendo contraído além do necessário; e de tempo, pois treinando continuamente na presença da tensão considerada desnecessária, o sujeito fica mais suscetível ao sofrimento de distúrbios, os quais provavelmente interromperão o processo de aprendizado. Por isso, o professor deve atentar à quantidade de força realizada pela criança, não devendo esta exceder um limite previamente estabelecido, de acordo com suas características físicas e morfológicas. Para tanto, vários fatores devem ser levados em consideração.

0 ensino do piano se adapta ao procedimento ergonômico quando o modelo do qual se serve considera: - a seleção de mecanismos e de repertórios apropriados às características individuais do aluno, como o tamanho de mão, plasticidade, idade, - aspectos posturais (colocação das mãos e do corpo em relação ao teclado), - programa de treinamento que tem por base a interação entre os aspectos técnicos, mecânicos e musicais. (PÓVOAS, 1999, p. 50-51).

Esses fatores, como dito, variam de acordo com o aluno, o que deve ser sempre lembrado na escolha de métodos auxiliares utilizados no ensino. "Cada discípulo apresenta características próprias e assim deve ser tratado individualmente, de acôrdo com a sua natureza." (FONTAINHA, 1956, p. 16). É impossível utilizar uma mesma abordagem para todos os alunos e é muito difícil encontrar algum método que se adeque otimamente a todos os conteúdos estudados em música e a todas as características apresentadas pelo estudante. Na maioria das vezes, para um mesmo aluno, o apropriado seria utilizar mais de um método. "As normas dão uma orientação e jamais devem substituir a observação e avaliação de cada criança." (GREGOR, 1991, p. 51).

Outro fator a ser levado em conta, dessa vez não relacionado diretamente ao corpo do indivíduo e sim ao do instrumento, é o peso das teclas (o termo peso, aqui, tem o sentido de resistência à pressão dos dedos). Como não há uma padronização para o peso das teclas dos pianos, ao visitar diversas escolas de música encontramos diferentes pianos com teclas de pesos variados, desde muito leves a muito pesadas. 0 ideal foge desses dois extremos. Destes, o mais preocupante, baseado no caso aqui discutido, é o piano com teclas muito pesadas. Neste caso, o esforço reproduzido pela criança durante as aulas, ou momentos de prática, será excessivo. Portanto, identificando tal problema, tem-se "solução relativamente simples na mera adaptação das condições do instrumento." (BLUM, 1995, apud FRANK; MÜHLEN, 2007, p. 190). 
Em relação à altura do banco do piano: “A aula não deve ter início antes que o professor constate se o banco está à altura conveniente, a qual terá que ser modificada conforme a constituição física de cada aluno. Isso é importantíssimo, sobretudo para uma boa aplicação da escola do pêso do braço [...]" (FONTAINHA, 1956, p. 22). A altura inadequada do banco pode atrapalhar o processo de movimento espontâneo que ocorre entre o braço e o tronco, que trabalham em conjunto na execução sonora. "0 braço garante a projeção do membro em relação ao tronco." (TUBIANA; THOMINE; MACKIN, 1996, p. 1) Quando a altura do banco está muito baixa, a liberdade de movimentos exercida pelo tronco permanece limitada. Se 0 caso for de altura excessiva, os braços estarão sempre tocando "de cima", o que diminui a variedade de possibilidades de toque e sonoridade.

Dependendo do tamanho e demais características da criança, pode ser previdente que o início do aprendizado seja processado num teclado, instrumento que costuma ter as teclas mais leves do que um piano. No caso de ela ter mãos muito pequenas e força insuficiente para abaixar as teclas de maneira confortável é aconselhável que ela passe a tocar o instrumento piano somente quando se mostrar fisicamente apta para realizar tal tarefa.

Além do peso das teclas do piano, é fundamental que seja observado 0 arco das mãos do aluno. A criança deve perceber, com o auxílio do professor, qual a posição das mãos mais adequada para tocar instrumentos de teclado. A postura ideal é muito semelhante, se não igual, à mão em seu estado natural, relaxado, quando a articulação metacarpofalangeana está à mostra. Muitos problemas técnicos que acompanham estudantes, e até mesmo profissionais, estão ligados à pratica do instrumento acompanhada de posturas indevidas, inclusive das mãos. Na figura 4 são mostradas a vista lateral dos arcos longitudinais e dos arcos transversais da mão. As áreas sombreadas mostram a parte fixa do esqueleto. (TUBIANA; THOMINE; MACKIN, 1996, p. 9).

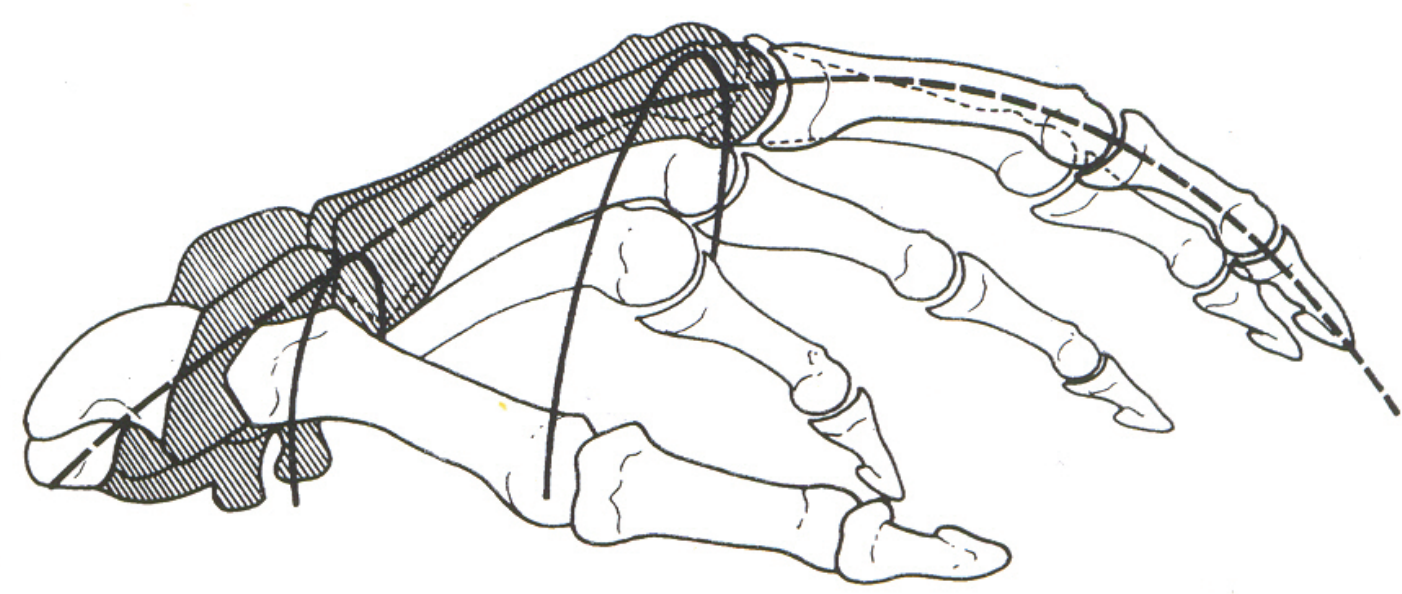

Figura 4. Arcos da mão em seu estado natural. Fonte: TUBIANA; THOMINE; MACKIN, 1996, p. 9 
Um problema comum ocorre quando a mão, estando em contato com o teclado, fica em tal posição que a articulação metacarpofalangeana fica abaixo dos vetores formados pelos quatro dedos; exceto o polegar. Esse problema fica bastante evidente em trechos executados em que a complexidade, ou a abertura da mão, exigida é significativa. Nesses casos nota-se com maior eficiência o arco da mão prevalecente no indivíduo.

A criança, geralmente, ao iniciar o estudo no piano, não dispondo ainda da resistência e independência nos dedos, é incapaz de conservá-los e também a mão, em sua forma arredondada e natural de repouso, ao abaixar as teclas do instrumento. Os seus dedos se quebram e a mão perde a sua forma arredondada, achatando-se completamente, devido ao esfôrço muscular. Podemos assim dizer que as anomalias da mão pianística, quase sempre, têm sua origem no início dos estudos. [...] 0 professor, entusiasmado, acelera demasiadamente os estudos, daí surgindo problemas que os dedos da criança ainda não estão em condições de resolver. Qual o resultado dessa prática? 0 exagerado esfôrço muscular aplicado na execução e, conseqüentemente, a deformação da posição da mão. Em geral, sempre que um aluno, mesmo adiantado, encontra uma grande dificuldade técnica a vencer, em vez de relaxar completamente os músculos dos braços, age em sentido opôsto, enervando-os, o que só lhe poderá trazer prejuízo. Aliás, isso ocorre também na prática de qualquer trabalho manual, quando ainda existe pouca experiência. (FONTAINHA, 1956, p. 55).

Porém, discorda-se de sua análise a respeito da musculatura durante a performance: "relaxar completamente os músculos dos braços". Entende-se que Richerme (1996, p. 74) apresenta uma leitura mais adequada da situação ideal durante a execução, através da crítica que faz a respeito desse tipo de abordagem errônea:

Embora muitos teóricos da técnica pianística não tivessem percebido, o relaxamento por eles pregado, num determinado movimento ou numa determinada posição, não significa a ausência de contração muscular, mas a ausência de fixação muscular, ou seja, a contração apenas dos músculos necessários para causar o movimento ou manter a posição.

A despeito do equívoco de considerar possível o relaxamento total do músculo durante a execução, Fontainha (1956, p. 41), através de seu método, propõe um exercício bastante interessante que trabalha esse "relaxamento total do músculo", porém como exercício de relaxamento, para ser exercido antes da execução ao piano. Tal exercício é de grande auxílio na implantação da consciência corporal no aluno iniciante:

A condição essencial para a aplicação da "Escola Moderna"12 é o relaxamento total dos músculos do braço. Assim, o primeiro exercício que

12 "A escola moderna não admite que se force a natureza do educando. Daí ser ela também denominada 'Escola natural' ou, ainda, 'Escola fisiológica'. “ (FOINTAINHA, 1956, p. 16). 
se impõe é o da ginástica respiratória, acompanhada da queda livre dos braços. [...] Essa prática é para o aluno acostumar a manter os braços com os músculos completamente relaxados, como se os mesmos não the pertencessem e estivessem apenas pendurados em seus ombros, sem qualquer ação muscular.

Esse exercício é de grande importância justamente para que o aluno perceba a sensação de ter os músculos do braço relaxados. A partir dessa consciência, ele pode passar a perceber quando está enrijecendo uma musculatura desnecessária à execução de determinado movimento ao piano.

Na imagem seguinte são exibidas duas situações comuns ao arco da mão: a linha contínua indica 0 arco natural da mão e a outra o problema bastante habitual, em que a posição dos dedos foge ao estado natural da mão e pode ser considerada problemática na prática pianística.

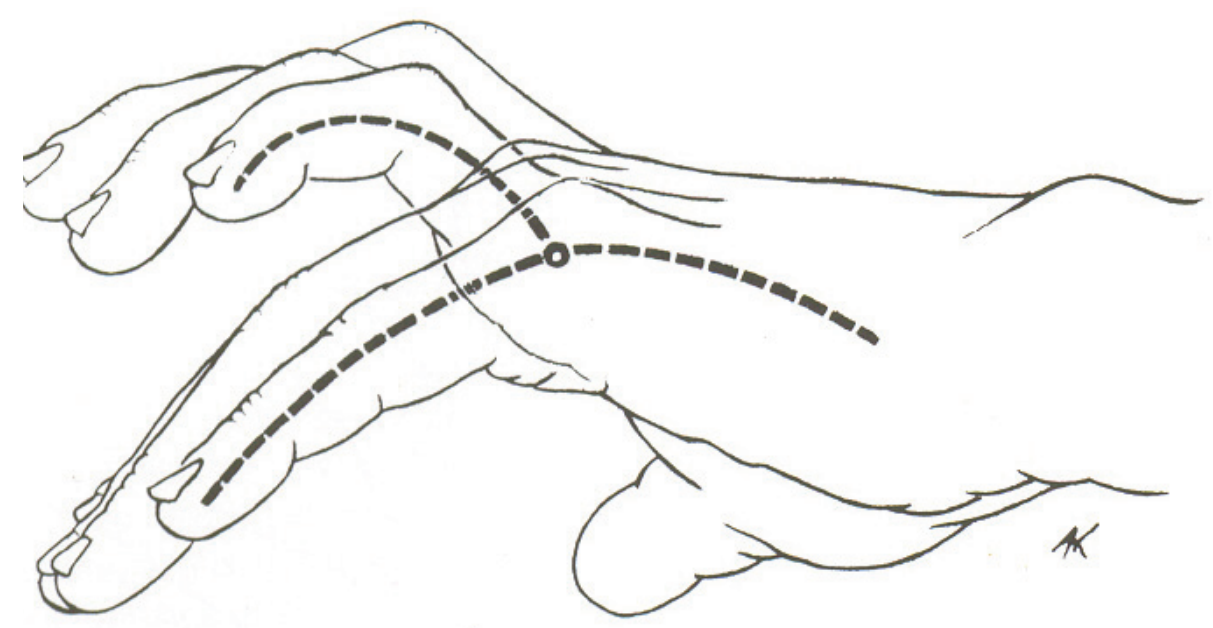

Figura 5. Arco longitudinal carpometacárpico vista do lado ulnar ${ }^{13}$ Fonte: TUBIANA; THOMINE; MACKIN, 1996, p. 14

Essas questões de técnica, relacionadas principalmente ao arco ideal da mão ao executar 0 instrumento, não se limitam apenas à infância, porém, é previdente que haja uma consciência a esse respeito desde o início do aprendizado. "Nenhuma epífise dos membros se funde antes da puberdade, mas todas as epífises normalmente estão fundidas antes dos 21 anos." (RASCH, 1991, p. 15). Ou seja, até aproximadamente os 21 anos, o sujeito ainda é suscetível a causar ou corrigir alguns erros técnicos elementares. Por isso há um período em que a correção de "vícios" ainda é válida e possível.

13 Ulna é o maior osso que forma o antebraço. É também conhecido como o "osso do cotovelo". 


\section{Considerações Finais}

Com base nas informações sobre os processos de formação óssea, especificamente dos ossos da mão, conclui-se que caso a criança venha a desenvolver sua técnica de piano, ou de qualquer instrumento, numa posição não ergonômica de mãos e dedos, pode ocorrer deformação dos centros de ossificação em processo de consolidação. Neste caso, seu estado final, a maturidade, será atingido de maneira que a posição/formato dos ossos estará inadequada. Esse acontecimento pode trazer danos irreversíveis à criança.

Ao ensinar piano a uma criança, o professor deve estar apto a analisar limitações e características físicas do aluno, ter conhecimento básico sobre as áreas que estudam o corpo humano, sua formação e capacidades, e estar suficientemente informado para propiciar uma formação técnica apropriada, evitando a ocorrência de problemas de desempenho e saúde. Infelizmente a preocupação com a saúde da criança nem sempre faz parte da formação técnica superior do professor de instrumento. Uma possível solução para que a conscientização desses assuntos ocorra, será incluir matérias que estudam esses conhecimentos específicos relacionados ao corpo humano em cursos de formação superior relacionados a tais assuntos, relevantes no âmbito da didática do piano.

0 respeito às formas e estados naturais do corpo permite o desenvolvimento adequado e funcional da técnica pianística em qualquer idade, portanto, é fator de relevância a ser considerado desde o princípio e nas fases subsequentes do aprendizado. Torna-se essencial a realização de pesquisas neste sentido. 


\section{Referências}

> Dicionário online de português. Disponível em: 〈http://www.dicio.com.br/>. Acesso em: 17 jun. 2012.

> FOINTAINHA, Guilherme Halfeld. 0 ensino do piano: Seus problemas técnicos e estéticos. $2^{a}$ ed. São Paulo: Carlos Wehrs đa Cia. Ltda., 1956.

> FRANK, Annemarie; MÜHLEN, Carlos Alberto von. Queixas Musculoesqueléticas em Músicos: Prevalência e Fatores de Risco. Revista Brasileira de Reumatologia, v. 47, n.3, p. 188-196, mai/jun, 2007

> Glossário, Médicos de Portugal. Disponível em: <http://medicosdeportugal. saude.sapo.pt/glossario/>. Acesso em: 5 ago. 2012.

> GREGOR, Robert. J. Neurologia, Cinestesia e Controle Servomotor. In: RASCH, Philip J. (Org.). Cinesiologia e anatomia aplicada. $7^{a}$ ed. Rio de Janeiro: Editora Guanabara Koogan S. A., 1991.

> GUTHRIE, Edwin Ray. The psychology of learning. Oxford: Harper, 1952.

> Lexico, dicionário de português online. Disponível em: 〈http://www.lexico.pt〉. Acesso em: 17 jun. 2012.

> MARCONDES, Eduardo. Idade Óssea em Pediatria. Pediatria, 1980, v. 2, p. 297-311.

> PÓVOAS, Maria Bernardete Castelan. Controle de movimento com base em um princípio de relação e regulação do impulso-movimento: Possíveis reflexos na otimização da ação pianística. Dissertação de Doutorado. UFRGS, Porto Alegre, 1999.

$>$ RASCH, Philip J. Cinesiologia e anatomia aplicada. $7^{a}$ d. Rio de Janeiro: Editora Guanabara Koogan S. A., 1991.

> RICHERME, Cláudio. Técnica pianística: uma abordagem científica. São João da Boa Vista, SP: AIR Musical Editora, 1996.

> TUBIANA, Raoul; THOMINE, Jean-Michel; MACKIN, Evelyn. Diagnóstico Clínico da Mão e do Punho. $2^{\mathrm{a}}$ ed. Rio de Janeiro: Interlivros Edições Ltda., 1996.

> Wikipedia, a enciclopédia livre. Diponível em: 〈http://pt.wikipedia.org/wiki/〉. Acesso em: 23 ago. 2012.

*Vinculado ao Projeto de Pesquisa "Técnica, movimento e coordenação motora - conceitos e aplicações interdisciplinares na ação pianística" desenvolvido no Centro de Artes/UDESC.

Maria Bernardete Castelan Póvoas, orientadora, Professora do Departamento de Música do CEART-UDESC

bernardetecastelan@gmail.com

Mariana Costa Chamas Tabacow, Acadêmica do Curso de Bacharelado em Música do CEART-UDESC, bolsista de iniciação científica PROBIC/CNPq.

marianatabacow@hotmail.com 